\title{
CL regression in the pseudopregnant rabbit and the effects of treatment with prostaglandin F-2 $\alpha$ and arachidonic acid
}

\author{
J. C. Carlson and J. W. D. Gole \\ Biology Department, University of Waterloo, Waterloo, Ontario, Canada N2L $3 G 1$
}

\begin{abstract}
Summary. During pseudopregnancy in the rabbit, plasma progesterone levels in the posterior vena cava fell rapidly from maximal concentrations of $9.8 \pm 0.7$ (s.e.m.) $\mathrm{ng} / \mathrm{ml}$ on Day 13 of pseudopregnancy to $2.0 \pm 0.6 \mathrm{ng} / \mathrm{ml}$ on Day 15 . There was no significant increase in PGF levels at this time, although administration of indomethacin to a similar group of does delayed functional regression for over 7 days. Subcutaneous injection of $1 \mathrm{mg}$ PGF-2 $\alpha$ or $35 \mathrm{mg}$ arachidonic acid on Day 9 of pseudopregnancy resulted in loss of luteal function as plasma progesterone levels fell significantly from about 6 to $<1 \mathrm{ng} / \mathrm{ml}$ within $24 \mathrm{~h}$. These findings indicate that the uterine factor responsible for luteolysis in the pseudopregnant rabbit may not be released in the form of PGF-2 $\alpha$.
\end{abstract}

\section{Introduction}

Hysterectomy delays CL regression in many laboratory and domestic animals. In the ewe, the uterine factor responsible for luteolysis is prostaglandin (PG) F-2 $\alpha$ : e.g. administration of this compound causes luteal regression, and, during the normal oestrous cycle, its release into the uterine vein is followed by a decline in progesterone secretion (McCracken, Baird \& Goding, 1971; Barcikowski, Carlson, Wilson \& McCracken, 1974). In addition, these authors have presented evidence that PGF-2 $\alpha$ is transported to the ovary from the adjacent uterine horn by local transfer between the utero-ovarian vein and ovarian artery. Such a mechanism bypasses systemic dilution and metabolism.

Less is known about $C L$ regression in the rabbit. In this species, PGF-2 $\alpha$ treatment causes luteolysis (Gutknecht, Duncan \& Wyngarden, 1972) and hysterectomy blocks the luteal regression which normally occurs at about Day 16 in pseudopregnant animals (Scott \& Rennie, 1970). However, in the rabbit there is no local utero-ovarian relationship (Hunter \& Casida, 1967) or apposition of the utero-ovarian vein and ovarian artery (Del Campo \& Ginther, 1972), and the question therefore arises of how the uterine luteolytic factor is transported to the ovary.

A possible explanation arises from the experiments of Hoffman (1974) who observed that arachidonic acid treatment significantly decreased CL weight in pseudopregnant rabbits, but CL size was maintained if indomethacin was administered concurrently. The luteolytic factor may therefore be transported to the ovary in the form of a precursor, such as arachidonic acid, and be converted at that site to PGF-2 $\alpha$, thus avoiding systemic inactivation.

The purpose of the present investigation was to test this hypothesis by examining the effects of PGF- $2 \alpha$, arachidonic acid and indomethacin administration on CL function, i.e. plasma progesterone concentrations.

\section{Materials and Methods}

The 28 mature female New Zealand White rabbits weighing 3-4 kgeach were housed individually in a room with $14 \mathrm{~h}$ light $/ 24 \mathrm{~h}$ and had free access to food and water. Before experiment, each animal was treated for 2 consecutive days with $50 \mu \mathrm{g}$ oestradiol benzoate subcutaneously and mated to a vasectomized buck on the 3 rd day (Day 0 of pseudopregnancy). Several days earlier an indwelling 
cannula had been inserted into the jugular vein and passed inferiorly into the posterior vena cava so that the tip was just anterior to the junction with the ovarian vein (checked at autopsy).

The rabbits were divided into 5 groups and all experiments were conducted in restrained conscious animals. Group 1 consisted of 9 animals treated with $1 \mathrm{mg}$ PGF-2 $\alpha$, Group 2 contained 4 animals injected with $35 \mathrm{mg}$ arachidonic acid, and the 6 animals in Group 3 received a control injection of vehicle only. The PGF- $2 \alpha$ and arachidonic acid were dissolved in a $0 \cdot 1 \mathrm{M}$-sodium phosphate buffer (pH 7.0) containing $15 \%$ gelatin and injected subcutaneously on the dorsal surface between the scapulae. Serial blood samples (1-2 ml) were withdrawn every hour for $17 \mathrm{~h}$ immediately after treatment and less frequently thereafter. All experiments began between 08:00 and 09:00 $h$ on Day 9 of pseudopregnancy. Group 4 contained 5 untreated rabbits which were bled daily from Days 1 to 19 of pseudopregnancy except Days 13-15 when more frequent samples were collected every 3-6 h; this was the period of functional CL regression. Group 5 included 4 pseudopregnant animals injected s.c. twice daily from Days 9 to 26 with $25 \mathrm{mg}$ indomethacin dissolved in oil. Daily blood samples were removed from Days 9 to 30 . Immediately after withdrawal all samples were mixed with heparin and the plasma stored frozen at $-10^{\circ} \mathrm{C}$ until assay. Packed cell volumes were measured during collection for all the animals but there was no marked decline in red blood cell volume.

\section{Progesterone assay}

Progesterone concentrations were measured by a radioimmunoassay similar to that described by Abraham, Swerdloff, Tulchinsky \& Odell (1971). The antiserum was raised in a sheep immunized to progesterone-11-bovine serum albumin and was examined for cross-reaction with $17 \alpha$-hydroxypregn-4-ene-3,20-dione, 20 $\alpha$-hydroxypregn-4-ene-3-one oestradiol-17 $\beta$ and testosterone, steroids which are secreted by the rabbit ovary (Hilliard, Spies \& Sawyer, 1968; Hilliard \& Eaton, 1971; Waterston \& Mills, 1976), and cholesterol and oestradiol benzoate. By using the calculation procedure of Abraham (1969), cross-reactivity was found to be less than $1 \%$ for each of the above compounds. Because of the specificity of the antiserum, the chromatography step was omitted. The progesterone tracer, $\left[1,2,6,7-{ }^{3} \mathrm{H}\right]$ progesterone (sp. act. $90-115 \mathrm{Ci} / \mathrm{mmol}$ ), was supplied by New England Nuclear Corporation. For extraction, $0 \cdot 1 \mathrm{ml}$ plasma was used and each sample was assayed in duplicate. To calculate procedural losses, 1000 c.p.m. of labelled progesterone were added to each plasma sample before extraction and an aliquot was removed before incubation with antiserum. Recoveries ranged from 85 to $92 \%$. To test for accuracy, various amounts of progesterone were added to $0.1 \mathrm{ml}$ plasma previously treated with charcoal to remove endogenous steroids. Addition of 50, 100, 200 and $300 \mathrm{pg}$ resulted in mean \pm s.e.m. $(n=10)$ estimates of $48 \cdot 4 \pm 7 \cdot 2,91 \cdot 3 \pm 3 \cdot 6,183 \cdot 3 \pm 10 \cdot 6$ and $290 \cdot 6 \pm 13.3 \mathrm{pg}$ of progesterone, respectively. Assay sensitivity was $50 \mathrm{pg} / \mathrm{ml}$ plasma. The intra- and inter-assay coefficients of variation were 5 and $8 \cdot 8 \%$ respectively.

\section{$P G F$ assay}

Plasma PGF levels were measured by using the radioimmunoassay procedure of Van Orden \& Farley (1973) except that the chromatography step was omitted. Initial assays with split samples tested with and without chromatography showed excellent agreement. The antiserum was prepared as described by Stylos, Burstein, Rivetz, Gunsalus \& Skarnes (1972) and examined for cross-reactivity (see Roberts, Carlson \& McCracken, 1976). In our laboratory, we have found this antiserum to be specific for PGF-2 $\alpha$ when tested with PGE-2 and the metabolites, 13,14-dihydroprostaglandin F-2 $\alpha$ and 13,14-dihydro-15-keto-prostaglandin F-2 $\alpha$. The tracer, $\left[5,6,8,9,11,12,14,15-{ }^{3} \mathrm{H}\right]$ prostaglandin F-2 $\alpha$ (sp. act. 100-150Ci/mmol), was obtained from New England Nuclear Corporation. Blood samples were mixed with the inhibitor of prostaglandin synthesis, indomethacin, at collection and $0.2 \mathrm{ml}$ plasma was extracted for assay. Each sample was divided into 1 aliquot for recovery estimations and 2 aliquots for duplicate determinations in the assay. Recoveries ranged from 77 to $92 \%$ and the inter- and intra-assay coefficients of variation were 6.2 and $4.5 \%$ respectively. PGF concentrations determined by this assay for jugular vein and carotid artery samples were $300-600 \mathrm{pg} / \mathrm{ml}$ and these values are similar to those reported by other workers for such samples. The arachidonic acid used for treatment of rabbits in Group 2 was tested in the PGF assay but no cross-reaction was found. 


\section{Results}

Subcutaneous injection of $1 \mathrm{mg}$ PGF-2 $\alpha$ caused a sharp drop in the posterior vena caval progesterone concentration in all rabbits in Group 1: the mean \pm s.e.m. values decreased from $6.5 \pm 1.8 \mathrm{ng} / \mathrm{ml}$ before treatment to $0.4 \pm 0.1 \mathrm{ng} / \mathrm{ml}$ by $24 \mathrm{~h}$ (Text-fig. 1a). A significant $(P<0.01)$ decline did not appear until $7 \mathrm{~h}$ after prostaglandin administration when progesterone concentration fell from $5.4 \pm 0.5 \mathrm{ng} / \mathrm{ml}$ at $6 \mathrm{~h}$ to $3.3 \pm 0.3 \mathrm{ng} / \mathrm{ml}$ at $7 \mathrm{~h}$. Thereafter, the drop was steady but more gradual. Similarly, a significant decline in progesterone levels also occurred in the Group 2 rabbits treated with arachidonic acid (Text-fig. 1b). Although the control rabbits in Group 3 displayed pronounced variation in plasma progesterone concentrations over the $24 \mathrm{~h}$ collection period (Days 9-10), the mean level of this steroid in posterior vena caval blood did not fall below $5.4 \mathrm{ng} / \mathrm{ml}$ (Text-fig. 1c). The PGF concentrations were 1.1-3.2, 1.3-2.4 and 1.3-1.7 ng/ml in Groups 1,2 and 3 respectively.

In Group 4, the plasma progesterone concentrations increased to maximum levels on Day 13 (Text-fig. 2) and then fell sharply over the next 2 days (Table 1). In the indomethacin-injected rabbits in Group 5 luteolysis was delayed for several days (Text-fig. 3); progesterone concentrations fell to below $1 \mathrm{ng} / \mathrm{ml}$ only after Day 26 of pseudopregnancy, about 10 days after these low values had been reached in the untreated rabbits (Group 4).

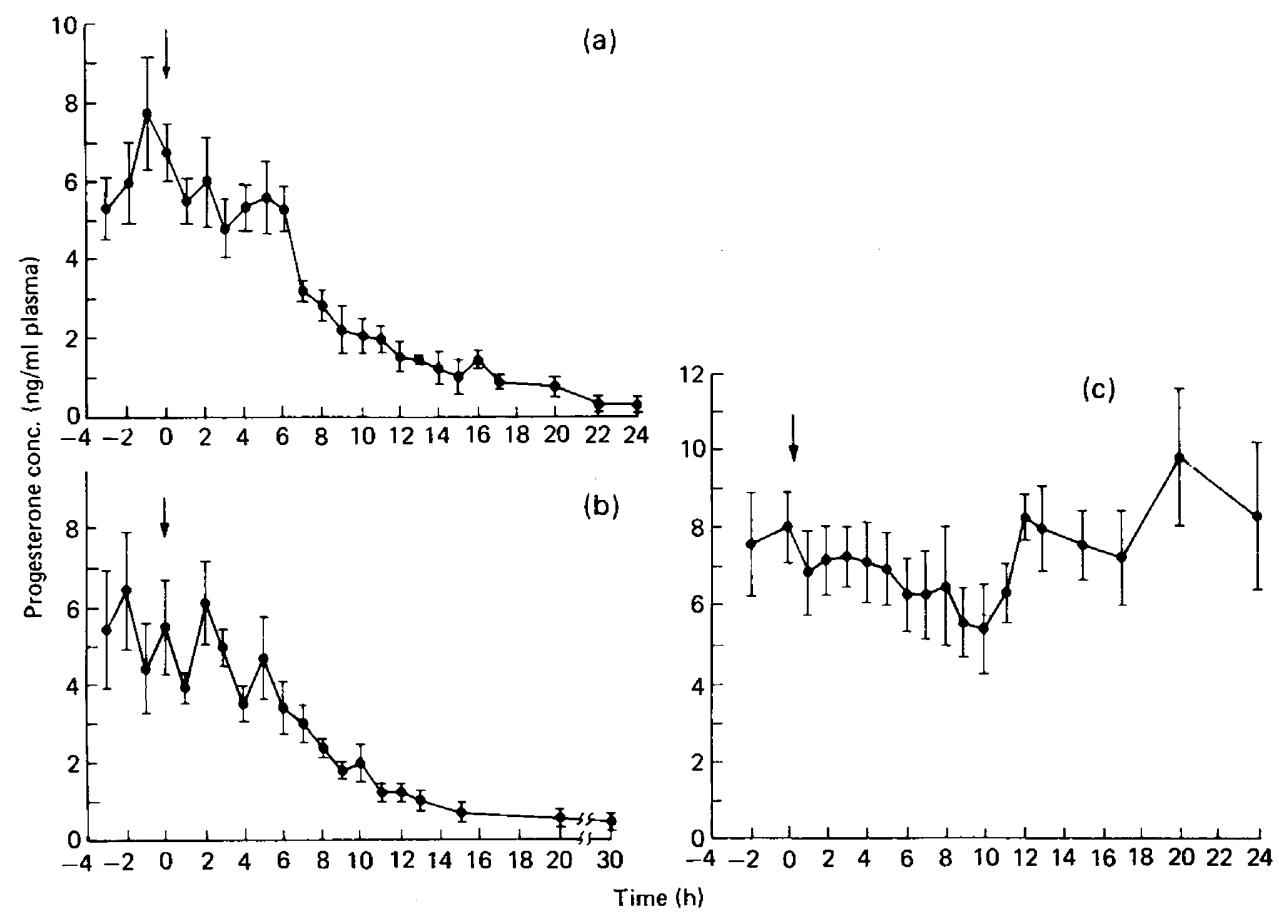

Text-fig. 1. The effect of subcutaneous injection of (a) $1 \mathrm{mg}$ PGF-2 $\alpha$, (b) $35 \mathrm{mg}$ arachidonic acid or (c) vehicle (gelatin) only on Day 9 of pseudopregnancy on progesterone concentrations in the posterior vena cava of rabbits. Values are mean \pm s.e.m. for 9 (a), 4 (b) and 6 (c) animals.

The concentrations of PGF in the rabbits in Groups 4 and 5 are shown in Text-figs 2 and 3 and Table 1. There was no significant change in PGF values at the end of normal pseudopregnancy (Day 14: Text-fig. 2 and Table 1). In Group 5, indomethacin treatment lowered plasma PGF concentrations more than $50 \%$, but progesterone levels still declined steadily after Day 17 . 


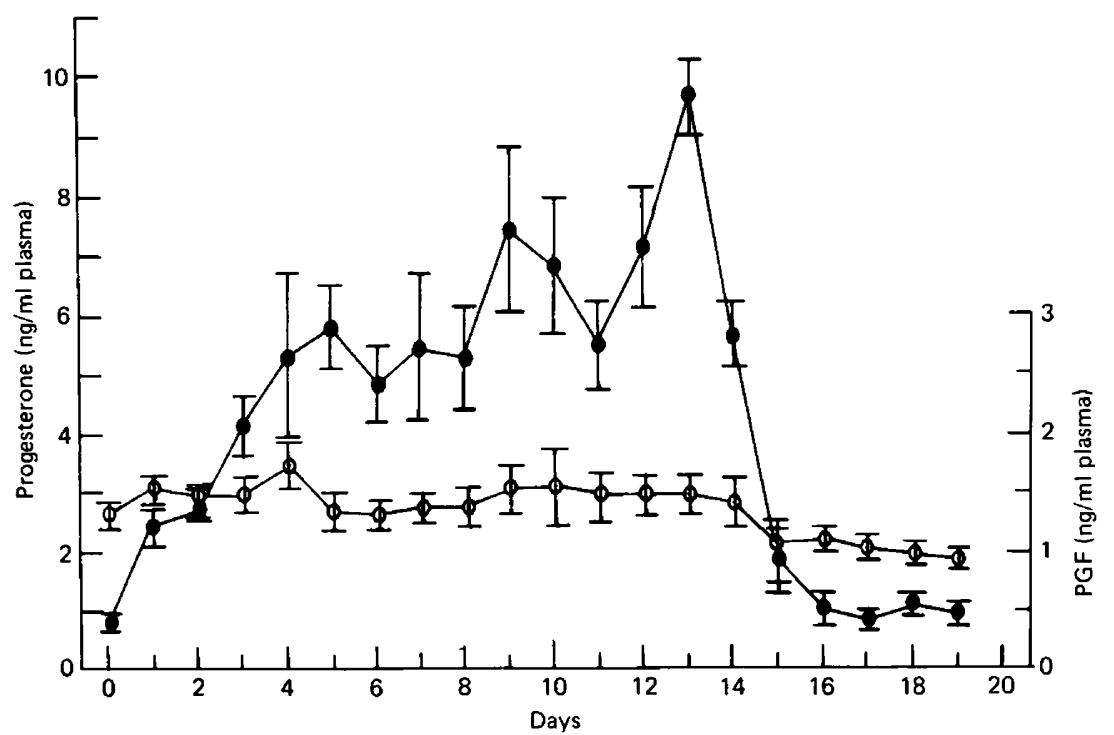

Text-fig. 2. Concentrations (mean \pm s.e.m.) of progesterone $(\bullet)$ and PGF $(0)$ in the posterior vena cava during pseudopregnancy in the rabbit. Each point represents the mean for all samples collected on that day for all the animals (5) in this group (Group 4).

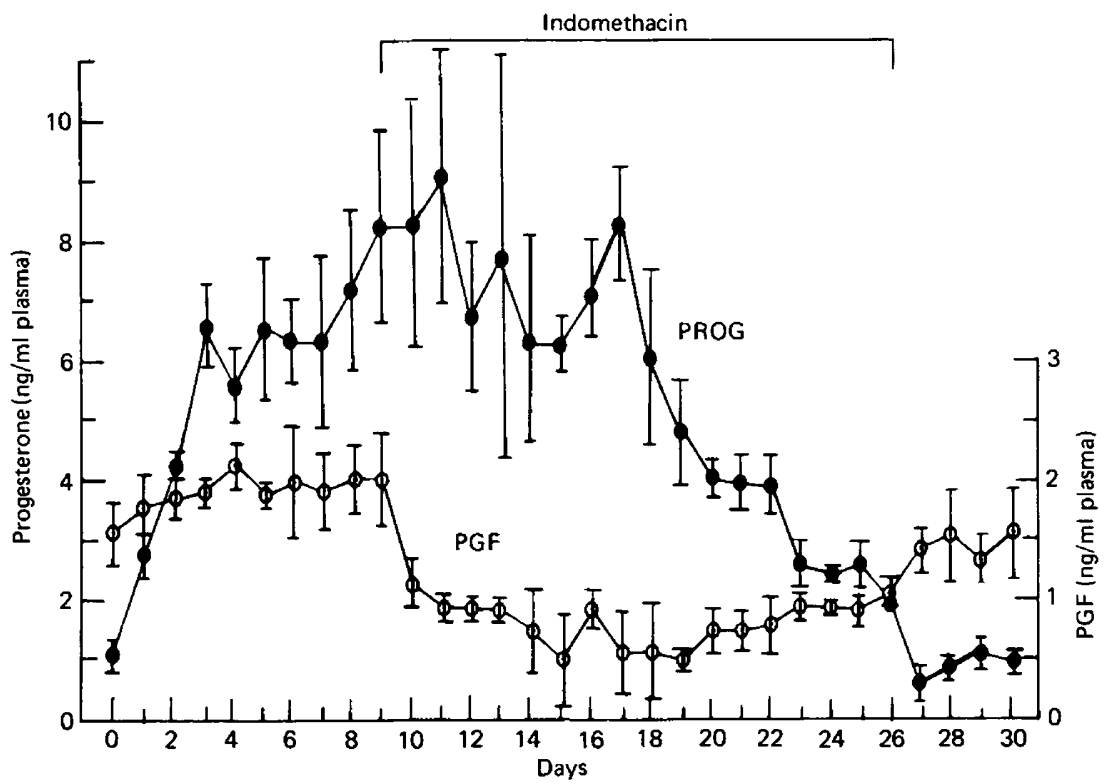

Text-fig. 3. The effect of indomethacin treatment (see text) during pseudopregnancy on posterior vena cava progesterone and PGF concentrations (mean \pm s.e.m., $\mathrm{N}=4$ ). Progesterone levels on Days 18-26 were significantly lower $(P<0.01)$ than on Days 8-17. Indomethacin administration significantly depressed $(P<0.01)$ PGF concentrations during the treatment period (Days 9-26).

\section{Discussion}

Administration of PGF-2 $\alpha$ or arachidonic acid to rabbits resulted in peripheral plasma progesterone concentrations falling to basal levels within $24 \mathrm{~h}$. These results confirm previous observations on morphological or functional changes of the $\mathrm{CL}$ after treatment of pseudopregnant rabbits with PG 
Table 1. Progesterone and PGF concentrations (mean \pm s.e.m. of 5 samples at each time) in blood samples collected from the posterior vena cava of pseudopregnant rabbits on Days 13 and 14 , i.e. during CL regression (Group 4)

\begin{tabular}{cccc}
\hline Day & Hour & Progesterone $(\mathrm{ng} / \mathrm{ml})$ & PGF $(\mathrm{ng} / \mathrm{ml})$ \\
\hline 13 & $06: 00$ & $8 \cdot 5 \pm 2 \cdot 8$ & $1 \cdot 3 \pm 0 \cdot 1$ \\
13 & $09: 00$ & $8 \cdot 3 \pm 1 \cdot 0$ & $1 \cdot 2 \pm 0 \cdot 1$ \\
13 & $12: 00$ & $12 \cdot 3 \pm 1 \cdot 8$ & $1 \cdot 7 \pm 0 \cdot 1$ \\
13 & $15: 00$ & $11 \cdot 0 \pm 1 \cdot 0$ & $1 \cdot 4 \pm 0 \cdot 1$ \\
13 & $18: 00$ & $8 \cdot 0 \pm 1 \cdot 7$ & $1 \cdot 4 \pm 0 \cdot 2$ \\
13 & $21: 00$ & $11 \cdot 2 \pm 1 \cdot 5$ & $1 \cdot 7 \pm 0 \cdot 2$ \\
13 & $24: 00$ & $8 \cdot 5 \pm 3 \cdot 7$ & $2 \cdot 2 \pm 0 \cdot 5$ \\
14 & $06: 00$ & $7 \cdot 8 \pm 0 \cdot 3$ & $1 \cdot 5 \pm 0 \cdot 2$ \\
14 & $12: 00$ & $8 \cdot 2 \pm 1 \cdot 0$ & $1 \cdot 2 \pm 0 \cdot 1$ \\
14 & $18: 00$ & $4 \cdot 6 \pm 1 \cdot 0 *$ & $2 \cdot 0 \pm 0 \cdot 4$ \\
14 & $24: 00$ & $2 \cdot 0 \pm 0 \cdot 2^{*}$ & $1 \cdot 0 \pm 0.4$ \\
\hline
\end{tabular}

* These values were significantly different from all earlier samples $P<0.01$.

or arachidonic acid (Scott \& Rennie, 1970; Gutknecht et al., 1972; Koering, 1974; Keyes \& Bullock, 1974; Hoffman, 1974), but also examined the sequential changes in plasma progesterone in each rabbit over a 24 -h period. Previous investigations have shown that the uterus is required for luteolysis at the normal time in rabbits (Scott \& Rennie, 1970; Hoffman, Davies \& Davenport, 1973) and that there is no evidence for a local transfer of a luteolytic substance between the uterus and adjacent ovary (Einer-Jensen, 1974). Our present findings are consistent with synthesis of arachidonic acid in the rabbit endometrium and systemic transport to the ovary for conversion to PGF-2 $\alpha$. Wilks, Hunter \& Norland (1972) have shown that the rabbit ovary is capable of synthesizing PGF-2 $\alpha$ de novo. However, measurement of circulating arachidonic acid levels during luteolysis in the doe are needed before a firm conclusion can be made about the method of transfer of the luteolytic substance in the rabbit.

In the rabbit, the delay between prostaglandin treatment and CL regression appears to be longer than in the ewe (McCracken, Glew \& Scaramuzzi, 1970; McCracken, Barcikowski, Carlson, Green $\&$ Samuelsson, 1973). Although detailed studies of the effect of treatment with PGF-2 $\alpha$ on progesterone secretion in the pseudopregnant rabbit have not been carried out, in the pregnant doe PGF-2 $\alpha$ causes an initial rapid drop $(50 \%)$ in plasma progesterone concentration within $2 \mathrm{~h}$, followed by a more gradual decline over the next 22 h (Bruce \& Hiller, 1974; Challis, Porter \& Ryan, 1974). This delay may be a reflection of species differences in the control of CL function. For example, oestradiol$17 \beta$ is responsible for direct luteotrophic support in the rabbit (Keyes \& Nalbandov, 1967) and it successfully antagonizes the luteolytic effect of PGF-2 $\alpha$ when both are administered together (Gutknecht et al., 1972; Keyes \& Bullock, 1974). In contrast, LH, the principle luteotrophic hormone in the ewe, is unable to prevent the CL regression caused by PGF- $2 \alpha$ when both are administered simultaneously (McCracken et al., 1973). Therefore, in the rabbit circulating levels of oestrogen may interfere temporarily with the luteolytic effect of PGF-2 $\alpha$ until ovarian levels of this prostaglandin are sufficient to overcome the luteotrophic stimulus.

In the present study, evidence of functional regression of the CL occurred between Days 14 and 15 of pseudopregnancy, 1 to 2 days before morphological evidence of regression was noted by Scott \& Rennie (1970) and Hoffman et al. (1973), but there was no significant increase in PGF concentrations in the posterior vena cava at this time. Similarly, Challis, Davies \& Ryan (1973) reported that the gradual fall in peripheral progesterone which began after Day 13 in the pregnant rabbit was unaccompanied by an increase in peripheral PGF levels. However, in the cyclic ewe Barcikowski et al. (1974) found several large peaks of PGF-2 $\alpha$ concentrations in the utero-ovarian vein before $\mathrm{CL}$ regression. It therefore seems unlikely that in the pseudopregnant rabbit the uterine luteolysin 
is released in the form of PGF- $2 \alpha$ unless it is altered to an active metabolite when it enters the uterine vein.

Loss of CL function occurred in pseudopregnant rabbits despite chronic indomethacin treatment. Similar observations have been made by O'Grady, Caldwell, Auletta \& Speroff (1972). The timing of the gradual decrease in progesterone secretion in indomethacin-treated animals coincides with the morphological changes observed for luteal tissue in hysterectomized, pseudopregnant does (Scott \& Rennie, 1970; Hoffman et al., 1973), and clearly the CL soon loses its ability to function when the luteolytic factor is removed by hysterectomy or blocked by an inhibitor. Although the mechanism responsible for regression at this time is unknown, it seems unlikely that it is related to a decline in circulating oestradiol-17 $\beta$ levels. Miller \& Keyes (1976) have reported that oestradiol implants, which maintained serum oestrogen at high concentrations, did not prevent CL regression in pseudopregnant does and the rabbit CL may lose its ability to respond to a luteotrophic stimulus, perhaps by the loss of an oestrogen receptor (Jacobson, Bullock \& Keyes, 1972).

We thank Dr J. S. Roberts, The Worcester Foundation, for the PG antiserum; Dr G. D. Niswender, Colorado State University, for the progesterone antiserum; and Dr J. E. Pike, The Upjohn Company, for the PGs. The work was supported by the National Research Council of Canada.

\section{References}

Abraham, G.E. (1969) Solid-phase radioimmunoassay of estradiol-17ß. J. clin. Endocr. Metab. 29, 866-870.

Abraham, G.E., Swerdloff, R., Tulchinsky, D. \& ODELL, W.D. (1971) Radioimmunoassay of plasma progesterone. J. clin. Endocr. Metab. 32, 619-624.

Barcikowski, B., Carlson, J.C., Wilson, L. \& MCCRACKeN, J.A. (1974) The effect of endogenous and exogenous estradiol-17 $\beta$ on the release of prostaglandin F-2 $\alpha$ from the ovine uterus. Endocrinology 95, 1340-1349.

Bruce, N.W. \& Hillier, K. (1974) The effect of prostaglandin F-2 $\alpha$ on ovarian blood flow and corpora lutea regression in the rabbit. Nature, Lond. 249, $176-177$.

Challis, J.R.G., Davies, I.J. \& Ryan, K.J. (1973) The relationship between progesterone and prostaglandin $F$ concentration in the plasma of pregnant rabbits. Prostaglandins 4, 509-516.

Challis, J.R.G., Porter, D.G. \& Ryan, K.J. (1974) The effects of prostaglandin F-2 $\alpha$ and ovariectomy on the peripheral plasma steroid concentrations and the evolution of myometrial activity in the pregnant rabbit. Endocrinology 95, 783-792.

Del CAmpo, C.H. \& Ginther, O.J. (1972) Vascular anatomy of the uterus and ovaries and the unilateral luteolytic effect of the uterus: guinea pigs, rats, hamsters, and rabbits. Am.J. vet. Res. 33, 2561-2578.

EINER-Jensen, N. (1974) Local transfer of ${ }^{133}$ xenon from the uterine horn to the ipsilateral ovary in the mouse, hamster and guinea-pig. J. Reprod. Fert. 40, 479-482.

Gutknecht, G.D., Duncan, G.W. \& Wyngarden, L.J. (1972) Inhibition of prostaglandin F-2 $\alpha$ or LH induced luteolysis in the pseudopregnant rabbit by $17 \beta$ estradiol. Proc. Soc. exp. Biol. Med. 139, $406-410$.

Hilliard, J. \& Eaton, L.W., JR (1971) Estradiol-17ß, progesterone and 20a-hydroxypregn-4-en-3-one in rabbit ovarian venous plasma. II. From mating through implantation. Endocrinology 89, 522-527.
Hilliard, J., Spies, H.G. \& Sawyer, C.H. (1968) Cholesterol storage and progestin secretion during pregnancy and pseudopregnancy in the rabbit. Endocrinology 82, 157-165.

Hoffman, L.H. (1974) Luteal regression induced by arachidonic acid in the pseudopregnant rabbit. J. Reprod. Fert. 36, 401-404.

Hoffman, L.H., Davies, J. \& Davenport, G.R. (1973) The effects of hysterectomy and decidual induction on luteal maintenance in rabbits. Endocrinology 93, 348-355.

Hunter, G.L. \& Casida, L.E. (1967) Absence of local effects of the rabbit uterus on weight of corpus luteum. J. Reprod. Fert. 13, 179-181.

Jacobsen, H.I., Bullock, D.W. \& KeYes, P.L. (1972) Effect of prostaglandin F-2 $\alpha$ on estrogen receptor in corpus luteum and uterus. Proc. 4th Int. Congr. Endocrinol., Washington, Abstr. 472. (Excerpta Medica Int. Congr. Ser. No. 256.)

KeYes, P.L. \& Bullock, D.W. (1974) Effects of prostaglandin F-2 $\alpha$ on ectopic and ovarian corpora lutea of the rabbit. Biol. Reprod. 10, 519-525.

KeYES, P.L. \& Nalbandov, A.V. (1967) Maintenance and function of corpora lutea in rabbits depend on estrogen. Endocrinology 80, 938-946.

KoERING, M.J. (1974) Luteolysis in normal and prostaglandin F-2 $\alpha$-treated pseudopregnant rabbits. J. Reprod. Fert. 40, 259-267.

McCracken, J.A., Glew, M.E. \& Scaramuzzi, R.J. (1970) Corpus luteum regression induced by prostaglandin F-2 $\alpha . J$. clin. Endocr. Metab. 30, 544-546.

MCCracken, J.A., Baird, D.T. \& Goding, J.R. (1971) Factors affecting the secretion of steroids from the transplanted ovary in the sheep. Recent Prog. Horm. Res. 27, 537-582.

McCracken, J.A., Barcikowski, B., Carlson, J.C., Green, K. \& Samuelsson, B. (1973) The physiological role of prostaglandin $\mathrm{F}-2 \alpha$ in corpus luteum regression. Adv. Biosci. 9, 599-624. 
Miller, J.B. \& Keyes, P.L. (1976) Progesterone synthesis in developing rabbit corpora lutea in the absence of follicular estrogens. Endocrinology 97, 83-90.

O'Grady, J.P., Caldwell, B.V., Auletta, F.J. \& Speroff, L. (1972) The effects of an inhibitor of prostaglandin synthesis (indomethacin) on ovulation, pregnancy, and pseudopregnancy in the rabbit. Prostaglandins 1, 97-106.

Roberts, J.S., Carlson, J.C. \& McCracken, J.A. (1976) Prostaglandin F-2 $\alpha$ production by the brain and its role in LH secretion. Adv. Prostaglandin \& Thromboxane Res. 2, 609-619.

ScOTT, R.S. \& RENNIE, P.I.C. (1970) Factors controlling the life-span of the corpora lutea in the pseudopregnant rabbit. J. Reprod. Fert. 23, 415-422.
Stylos, W., Burstein, S., Rivetz, B., Gunsalus, P. \& SkARNES, R. (1972) The production of anti-F prostaglandin serum and its use in radioimmunoassay. Intra-Sci. Chem. Rep. 6, 67-71.

VAN Orden, D.E. \& Farley, D.B. (1973) Prostaglandin $\mathrm{F}-2 \alpha$ radioimmunoassay utilizing polyethylene glycol separation technique. Prostaglandins 4, 215-232.

WATERston, J.W. \& Mills,T.M. (1976) Peripheral blood steroid concentrations in the preovulatory rabbit. J. Steroid Biochem. 7, 15-17.

Wilks, J.W., Hunter, K.K. \& Norland, J.F. (1972) Prostaglandin F-2 $\alpha$ synthesis by the rabbit ovary, uterus, and uterine cervix. Biol. Reprod. 7, 16, Abstr.

Received 23 December 1977 